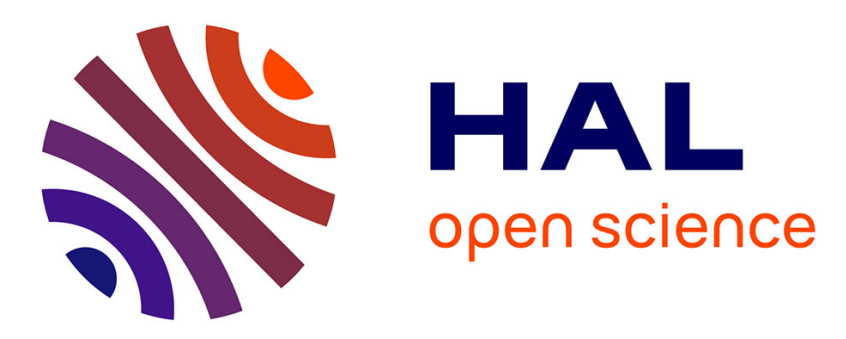

\title{
Untreated patients with multiple sclerosis: A study of French expert centers
}

Xavier Moisset, Audrey-Anne Fouchard, Bruno Pereira, Frederic Taithe, Guillaume Mathey, Gilles Edan, Jonathan Ciron, Bruno Brochet, Jerome de Seze, Caroline Papeix, et al.

\section{To cite this version:}

Xavier Moisset, Audrey-Anne Fouchard, Bruno Pereira, Frederic Taithe, Guillaume Mathey, et al.. Untreated patients with multiple sclerosis: A study of French expert centers. European Journal of Neurology, 2021, 28 (6), pp.2026-2036. 10.1111/ene.14790 . hal-03188971

\section{HAL Id: hal-03188971 \\ https://hal.science/hal-03188971}

Submitted on 21 Apr 2021

HAL is a multi-disciplinary open access archive for the deposit and dissemination of scientific research documents, whether they are published or not. The documents may come from teaching and research institutions in France or abroad, or from public or private research centers.
L'archive ouverte pluridisciplinaire HAL, est destinée au dépôt et à la diffusion de documents scientifiques de niveau recherche, publiés ou non, émanant des établissements d'enseignement et de recherche français ou étrangers, des laboratoires publics ou privés. 


\section{Untreated patients with multiple sclerosis: a study of French expert centers.}

*Xavier Moisset MD1 , *Audrey-Anne Fouchard MD¹, Bruno Pereira $\mathrm{PhD}^{1}$, Frédéric Taithe MD ${ }^{1}$, Guillaume Mathey $\mathrm{MD}^{2}$, Gilles Edan $\mathrm{MD}^{3}$, Jonathan Ciron $\mathrm{MD}^{4}$, Bruno Brochet $\mathrm{MD}^{5}$, Jérôme De Sèze $\mathrm{MD}^{6}$, Caroline Papeix $\mathrm{MD}^{7}$, Patrick Vermersch $\mathrm{MD}^{8}$, Pierre Labauge MD 9 , Gilles Defer $\mathrm{MD}^{10}$, Christine Lebrun-Frenay $\mathrm{MD}^{11}$, Thibault Moreau $\mathrm{MD}^{12}$, David Laplaud $\mathrm{MD}^{13}$, Eric Berger $\mathrm{MD}^{14}$, Jean Pelletier MD ${ }^{15}$, Bruno Stankoff $\mathrm{MD}^{16}$, Olivier Gout $\mathrm{MD}^{17}$, Eric Thouvenot $\mathrm{MD}^{18}$, Olivier Heinzlef $\mathrm{MD}^{19}$, Abdullatif Al-Khedr $\mathrm{MD}^{20}$, Bertrand Bourre MD ${ }^{21}$, Olivier Casez MD 22 , Philippe Cabre $\mathrm{MD}^{23}$, Alexis Montcuquet $\mathrm{MD}^{24}$, Alain Créange $\mathrm{MD}^{25}$, Jean-Philippe Camdessanché $\mathrm{MD}^{26}$, Serge Bakchine MD²7, Aude Maurousset MD ${ }^{28}$, Karolina Hankiewicz $\mathrm{MD}^{29}$, Corinne Pottier MD ${ }^{30}$, Nicolas Maubeuge MD ${ }^{31}$, Dalia Dimitri Boulos $\mathrm{MD}^{32}$, Chantal Nifle $\mathrm{MD}^{33}$, Sandra Vukusic $\mathrm{MD}^{34}$, and Pierre Clavelou $\mathrm{MD}^{1}$ on behalf of the OFSEP investigators.

*contributed equally to the work

1- Université Clermont Auvergne, CHU de Clermont-Ferrand, Inserm, Neuro-Dol, F-63000 ClermontFerrand, France.

2- Department of Neurology, Nancy University Hospital, F-54035 Nancy, France; Université de Lorraine, EA 4360 APEMAC, F-54500 Vandoeuvre-Lès-Nancy, France.

3- CHU Pontchaillou, CIC1414 INSERM, F-35000 Rennes, France.

4- CHU de Toulouse, Department of Neurology, CRC-SEP, F-31000 Toulouse, France.

5- Univ. Bordeaux, F-33000 Bordeaux; INSERM U1215, Neurocentre Magendie, F-33000 Bordeaux; CHU de Bordeaux, CIC Bordeaux CIC1401, F-33000 Bordeaux, France.

6- CHU de Strasbourg, Department of Neurology and Clinical Investigation Center, INSERM 1434, F67000 Strasbourg, France.

7- APHP, Pitié-Salpêtrière Hospital, Department of Neurology, F-75013 Paris.

8- Univ. Lille, INSERM UMR-S1172, CHU Lille, FHU Imminent, F-59000, Lille, France.

9- CHU de Montpellier, MS Unit, F-34295 Montpellier Cedex 5, France; University of Montpellier (MUSE), F-34000 Montpellier, France.

10- CHU de la Côte de Nacre, Department of Neurology, F-14000 Caen, France.

11- CHU de Nice; UR2CA, Nice Cote d'Azur University, CRCSEP Nice, Pasteur2 Hospital, F-06000 Nice, France.

12- CHU de Dijon, Department of Neurology, EA4184, F-21000 Dijon, France.

This article has been accepted for publication and undergone full peer review but has not been through the copyediting, typesetting, pagination and proofreading process, which may lead to differences between this version and the Version of Record. Please cite this article as doi: 
13- CHU de Nantes, Service de Neurologie \& CIC015 INSERM, F-44093 Nantes, France; INSERM CR1064, F-44000 Nantes, France.

14- CHU de Besançon, Service de Neurologie, F-25030 Besançon, France.

15- Aix Marseille Univ, APHM, Hôpital de la Timone, Pôle de Neurosciences Cliniques, Service de Neurologie, Marseille, France.

16- Assistance publique des hôpitaux de Paris, Hôpital Saint-Antoine, Service de neurologie, Paris, France.

17- Fondation Rotschild, Department of Neurology, F-75000 Paris, France.

18- Department of Neurology, Nîmes University Hospital, Nîmes, France; and Institut de Génomique Fonctionnelle, Université de Montpellier, CNRS , INSERM, Montpellier, France.

19- Hôpital de Poissy, Departement of Neurology, F-78300 Poissy, France.

20- Centre hospitalier universitaire d'Amiens Picardie, Site sud, Service de neurologie, Amiens, France.

21- CHU de Rouen, F-76000 Rouen, France / Rouen University Hospital, F-76000 Rouen, France.

22- Centre hospitalier universitaire Grenoble-Alpes, Site nord, Service de neurologie, Grenoble/La Tronche, France.

23- Centre hospitalier universitaire de Martinique, Hôpital Pierre Zobda-Quitman, Service de Neurologie, Fort-de-France, France.

24- CHU de Limoges, Hôpital Dupuytren, Department of Neurology, F-87042 Limoges, France.

25- Assistance publique des hôpitaux de Paris, Hôpital Henri Mondor, Service de neurologie, Créteil, France.

26- CHU de Saint-Étienne, Hôpital Nord, Department of Neurology, F-42055 Saint-Étienne Cedex 2, France

27- Centre hospitalier universitaire de Reims, Hôpital Maison-Blanche, Service de neurologie, Reims, France.

28- CHU de Tours, Hôpital Bretonneau, CRC SEP and Department of Neurology, F-37000 Tours, France.

29- Centre hospitalier de Saint-Denis, Service de neurologie, Saint-Denis, France.

30- Centre hospitalier de Pontoise, Service de neurologie, Pontoise, France.

31- Centre hospitalier universitaire de Poitiers, Site de la Milétrie, Service de neurologie, Poitiers, France.

32- Assistance publique des hôpitaux de Paris, Hôpital Bicêtre, Service de neurologie, Le Kremlin-Bicêtre, France.

33- Centre hospitalier de Versailles, Hôpital André-Mignot, Service de neurologie, Le Chesnay, France.

34- Service de Neurologie, Sclérose en Plaques, Pathologies de la Myéline et Neuro-Inflammation, Hôpital Neurologique Pierre Wertheimer, Hospices Civils de Lyon, 69677 Lyon/Bron, France; Centre des Neurosciences de Lyon, Observatoire Français de la Sclérose en Plaques, INSERM 1028 et CNRS UMR5292, 69003 Lyon, France; Université Claude Bernard Lyon 1, Faculté de Médecine Lyon Est, F69000 Lyon, France. 
Correspondance to :

Xavier MOISSET - Service de Neurologie, CHU Gabriel Montpied

58 rue Montalembert, F-63000 Clermont-Ferrand - France

E-mail: xavier.moisset@gmail.com

Tel: +33473752201 - Fax: +33473752202

Key words: Multiple sclerosis; untreated; unmet medical needs; progressive; relapsingremitting 
DR. XAVIER MOISSET (Orcid ID : 0000-0002-8799-0750)

DR. GUILLAUME MATHEY (Orcid ID : 0000-0002-5747-9169)

DR. CAROLINE PAPEIX (Orcid ID : 0000-0003-4074-6125)

DR. ALEXIS MONTCUQUET (Orcid ID : 0000-0002-7202-0399)

PROF. ALAIN CRÉANGE (Orcid ID : 0000-0003-3838-1622)

DR. JEAN-PHILIPPE CAMDESSANCHÉ (Orcid ID : 0000-0002-5282-6707)

Article type : Original Article

\section{Abstract}

Background: Disease modifying therapies (DMTs), have an impact on relapses and disease progression. Nonetheless, many patients with multiple sclerosis (pwMS) remain untreated. The objective of the present study was to determine the proportion of untreated patients with multiple sclerosis (pwMS) followed in expert centers in France and determine the predictive factors of non-treatment.

Methods: Retrospective cohort study. Data were extracted from the 38 centers participating in the European Database for Multiple Sclerosis (EDMUS) on 12/15/2018 and pwMS seen at least once during the study period (from June 15, 2016 to June 14, 2017) were included.

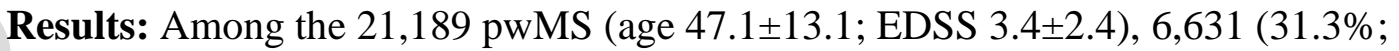
95\% CI=30.7-31.9) of the patients were not receiving any DMT. Although patients with a relapsing-remitting course $(\mathrm{n}=11,693)$ were the most likely to receive DMT, $14.8 \%(95 \% \mathrm{CI}$ $=14.2-15.4)$ were still untreated (6.8\% never treated). After multivariate analysis among relapsing-remitting pwMS, the main factors explaining never having been treated were not having $\geq 9$ lesions on brain MRI $(\mathrm{OR}=0.52[0.44-0.61])$ and lower $\operatorname{EDSS}(\mathrm{OR}=0.78[0.74$ 0.82]). Most patients with progressive MS (50.4\% for secondary and $64.2 \%$ for primary 
progressive MS) did not receive any DMT during the study period, $11.6 \%$ for secondary and $34.0 \%$ for primary progressive MS had never received any DMT.

Conclusion: A significant proportion of pwMS did not receive any DMT, even though such treatments are reimbursed by the healthcare system for French patients. This result highlights the unmet need for current DMTs for a large subgroup of pwMS. 


\section{Introduction}

It is now well-recognized that disease modifying therapies (DMTs), especially those that are more effective, have a major impact on relapses and even disease progression ${ }^{1-3}$. Thus, DMTs should be proposed as soon as possible after a diagnosis of multiple sclerosis (MS), including patients with clinically isolated syndrome (CIS) that fulfills the current diagnostic criteria for $\mathrm{MS}^{4,5}$. As recommended, it is also possible to offer DMT to patients with CIS and an abnormal MRI with lesions suggestive of MS who do not fulfill MS criteria ${ }^{4}$. Estimates of the number of patients with MS (pwMS) who remain untreated post-diagnosis are very limited, with $28 \%$ in a large cohort of Danish patients and $43 \%$ in the USA ${ }^{6}$. In France, DMTs are fully reimbursed by the health care system for all the patients, which is not the case in most countries in the world ${ }^{7}$. Nonetheless, many patients remain untreated.

Certain situations can explain why patients are untreated. Some patients have never been treated, either as no DMT was proposed or a DMT was proposed but declined. Other patients may have tried one or more DMTs and stopped for multiple reasons, in particular side effects or inefficacy. Finally, some patients may be waiting to initiate DMT. As DMTs are very expensive in many countries, costing more than $\$ 70,000$ per year for most in the USA, the cost can obviously be a limiting factor for access ${ }^{8}$. In France, pwMS have access to DMTs at no personal expense. Thus, the cost has no impact on the treatment decision and receiving a DMT relies on the efficacy and side effects of the DMT and the preference of the patient.

We aimed to assess the proportion of untreated pwMS followed in MS expert centers in France and define predictive factors for not being treated. 


\section{Patients and Methods}

Study design

This study was carried out in MS expert centers participating in the Observatoire Français de la Sclérose en Plaques (OFSEP) and collecting a minimal set of data prospectively at each visit for their local node of the European Database for Multiple Sclerosis (EDMUS) ${ }^{9,10}$ (see Appendix 1 for protocol approval, registration and obtention of patient consent).

\section{Data collection}

OFSEP gathers data on patients with MS collected by all French expert MS centers and MS networks routinely using EDMUS software as a medical file for all their MS patients ${ }^{9}$. Patients are included when diagnosed with MS according to ongoing criteria, with no age limit. Clinical data are retrospectively collected at the first visit and prospectively thereafter during routine follow-up visits, usually at least once a year. Data collection is based on a minimal required dataset, including demographic and socioeconomic characteristics and a description of the MS and DMTs, although much more data can be collected at the investigator's discretion.

The centralized data were extracted from the EDMUS database on December $15^{\text {th }}, 2018$.

\section{Definition of outcome measures}

The primary outcome was the proportion of patients who did not receive any DMT during the one-year timeframe (from June 15, 2016 to June 14, 2017), including DMTs received during clinical trials.

The secondary outcomes consisted of those necessary to define the predictive factors for not being treated. Thus, demographic data (age, gender, follow-up center), disease data (disease course, duration of MS, EDSS, number of lesions on the latest brain MRI, relapses during the five years prior to the period of interest), and treatment data (previous DMTs with reasons for discontinuation and DMTs initiated after the study period, duration of DMT use) were recorded. Three treatment groups were defined: currently-treated patients (pwMS receiving a DMT during the study period), currently-untreated patients (pwMS not receiving any DMT during the study period but who received a DMT either before or after this period of time), and never-treated patients.

Statistical analysis 
Univariate and multivariable analyses were conducted to predict the risk of being untreated taking into account center as random-effect (see Appendix 2 for further details). A two-sided $\mathrm{p}$ value $<0.05$ was considered statistically significant and no correction for familywise error was performed for exploratory analyses ${ }^{11}$. As proposed by Feise, particular attention was given to effect size and not only to statistical significance ${ }^{12}$. All analyses were performed using Stata (version 15, StataCorp, College Station, USA) software.

We additionally used R (R Core Team, 2020) with rpart to perform a decision-tree based analysis $^{13}$. Complexity parameter (cp) was set using printcp to define the optimal number of nodes of the tree.

\section{Data availability statement}

The data that support the findings of this study are available from the corresponding author upon reasonable request.

\section{Results}

During the study period (June 15, 2016 to June 14, 2017), 22,252 patients were seen at least once in one of the participating French MS centers and 21,189 were eligible for the present study (Figure 1). Among them, 14,558 (68.7\%, 95\%CI=68.1-69.3) were receiving a DMT (currently treated patients), 3,122 $(14.7 \%, 95 \% \mathrm{CI}=14.3-15.2)$ had never used a DMT (untreated patients), and 3,509 $(16.6 \%, 95 \% \mathrm{CI}=16.1-17.1)$ had received treatment outside the study period (currently untreated, $174(0.8 \%)$ received a DMT in the 6 months after the period of interest, whereas others had been treated before study period). Thus, $31.3 \%$ (95\% CI=30.7-31.9) of the patients were not receiving any DMT during the one-year timeframe of the study, including $14.8 \%(95 \% \mathrm{CI}=14.2-15.4)$ of patients with RR-MS. Among the centers with at least 50 patients seen during the study period (33/38), the proportion of never-treated patients varied from 10.4 to $25.4 \%$. Similarly, the proportion of untreated patients varied from 17.8 to $42.6 \%$. A decision tree-based analysis was performed and showed that the most important parameter explaining never having been treated was the disease course (see Figure S1). Indeed, patients with RR- or SP-MS were more likely to have tried at least one treatment. 
Demographic and clinical characteristics of the overall population and the three sub-groups according to DMT status are presented in Table 1. As there is an obvious difference in DMT use according to the disease course, the characteristics of the included patients are presented in specific tables for each disease course.

\section{Relapsing remitting $M S$}

Never treated RR-MS patients had a milder disease course, as shown by a longer duration of disease, a lower EDSS, a lower ARR, and a smaller number of lesions on brain MRI than currently treated RR-MS patients (Table 2). Currently treated RR-MS patients had been treated for $60.8 \%$ of the time since MS onset (first DMT initiated 4.6 \pm 5.9 years after disease onset, $0.29 \pm 0.64$ relapse during the year before initiation of the current DMT) and previously treated patients had been treated for $36.3 \%$ of the time. Previously treated RR-MS patients had received a median number of two DMTs (IQR [1 - 3]). They mainly stopped their DMTs due to side effects (39\%), a scheduled stop (18\%), inefficacy (16\%), personal convenience $(15 \%)$, or pregnancy (7\%). DMTs most frequently used for current and past users are presented in Table S1.

After multivariate analysis, the probability of never having been treated was explained by not having $\geq 9$ lesions on brain MRI (OR=0.52 [0.44-0.61]), lower EDSS (OR=0.78 [0.74-0.82]), and higher age $(\mathrm{OR}=1.04$ [1.03-1.05]). The probability of having stopped a previous DMT and being currently untreated was explained by not having $\geq 9$ lesions on brain MRI $(\mathrm{OR}=0.70$ [0.60-0.82]), being female $(\mathrm{OR}=1.34$ [1.11-1.61]), lower ARR $(\mathrm{OR}=0.88$ [0.800.97]), higher EDSS (OR=1.07 [1.03-1.12]), longer disease duration ( $\mathrm{OR}=1.02$ [1.01-1.03]), and higher age $(\mathrm{OR}=1.03$ [1.02-1.03]).

\section{Single relapse}

Patients with a single relapse were younger than RR-MS patients (Table 3). Never-treated patients had less frequently $\geq 9$ lesions on brain MRI and a median disease duration of only 1.1 years, whereas previously treated patients had been followed for much longer (median of 7.2 years) and still had a low EDSS. Currently-treated patients and those initiating a DMT in the following six months were more prone to have fulfilled all of the 2010 McDonald criteria at the last follow-up visit than untreated patients. Previously treated patients with a single 
relapse received a median number of one DMT (IQR [1 - 2]), which was stopped mainly due to side effects (39\%), personal convenience (23\%), a scheduled stop (21\%), pregnancy $(10 \%)$, or inefficacy (4\%). Currently-treated patients had used a DMT for $70.5 \%$ of the time since the single relapse (first DMT initiated 1.4 \pm 2.7 years after the event), whereas previously treated patients had used a DMT for $43.4 \%$ of the time. DMTs most frequently used for current and past users are presented in Table S1.

After multivariate analysis, the probability of never having been treated was explained by not fulfilling the $2010 \mathrm{McDonald}$ criteria at last follow-up ( $\mathrm{OR}=0.37$ [0.31-0.45]), not having $\geq 9$ lesions on brain MRI (OR=0.41 [0.34-0.50]), shorter disease duration ( $\mathrm{OR}=0.90$ [0.88-0.93]), and higher age $(\mathrm{OR}=1.02$ [1.01-1.03]). The probability of having stopped a previous DMT and being currently untreated was explained by longer disease duration only $(\mathrm{OR}=1.11$ [1.07$1.14])$.

\section{Secondary progressive $M S$}

Untreated SP-MS patients were older, with a longer duration of disease, in particular those who had never been treated (Table 4). They had a lower ARR during the preceding five years. Previously treated SP-MS patients had the highest EDSS and the lowest relapse rate. They had received a median of three DMTs (IQR [2-4]). They mainly stopped their DMTs due to inefficacy (32\%), a scheduled stop (26\%), side effects (22\%), personal convenience $(8 \%)$, or pregnancy $(0.4 \%)$. Currently-treated SP-MS patients had spent $53.5 \%$ of the time using a DMT since disease onset (first DMT initiated 9.0 \pm 8.5 years after disease onset, 0.08 \pm 0.30 relapse during the year prior current DMT initiation), whereas previously treated patients had received a DMT for $32.0 \%$ of the time. DMTs most frequently used for current and past users are presented in Table S1.

After multivariate analysis, as for the RR-MS patients, the probability of never having been treated was explained by: lower ARR (OR=0.64 [0.50-0.82]), lower EDSS (OR=0.71 [0.66$0.77])$, and higher age $(\mathrm{OR}=1.06$ [1.05-1.08]). The probability of having stopped a previous DMT and being currently untreated was explained by lower ARR $(\mathrm{OR}=0.70$ [0.61-0.81]), higher EDSS ( $\mathrm{OR}=1.44$ [1.36-1.52]), longer disease duration ( $\mathrm{OR}=1.02$ [1.01-1.02]), and higher age $(\mathrm{OR}=1.02[1.01-1.03])$.

\section{Primary progressive $M S$}


Never treated PP-MS patients were significantly older and had a statistically lower EDSS, although the difference was not clinically meaningful (Table 5). They had had fewer relapses during the five previous years. Previously-treated patients were older, with a higher EDSS and a lower relapse rate than those being currently treated. They had received a median of two DMTs (IQR [1 - 3]). They mainly stopped their DMT due to inefficacy (33\%), a scheduled stop (30\%), side effects $(21 \%)$, personal convenience $(7 \%)$, or pregnancy $(0.1 \%)$. Currently-treated PP-MS patients had spent $44.7 \%$ of the time using a DMT since disease onset (initiated 5.8 \pm 5.7 years after disease onset, $0.09 \pm 0.31$ relapse during the year prior to current DMT initiation), whereas previously treated patients had received a DMT for $26.8 \%$ of the time. DMTs most frequently used for current and past users are presented in Table S1. After multivariate analysis, the probability of never having been treated was explained by a lower EDSS (OR=0.74 [0.69-0.79]), higher age (OR=1.05 [1.04-1.06]), and shorter disease duration (OR=0.97 [0.96-0.99]). The probability of having stopped previous DMT and being currently untreated was explained by a higher EDSS (OR=1.51 [1.40-1.63]), lower ARR $(\mathrm{OR}=0.73$ [0.55-0.98]), and longer disease duration $(\mathrm{OR}=1.04$ [1.03-1.05]). 


\section{Discussion}

In this nation-wide, tertiary care-center study, $31 \%$ of pwMS were not receiving a DMT during the one-year study period (June 2016 to June 2017) and 15\% had never received any DMT. Even taking only patients with RR-MS into account, 7\% had never received any DMT and $15 \%$ were not being treated during the study period. Moreover, even currently-treated patients were quite far from having been treated all the time since disease onset $(61 \%$ of the time for currently-treated RR-MS patients). Nearly $40 \%$ of patients with a single relapse and RR-MS patients that were previously treated stopped their DMT due to side effects. The patients that were less likely to receive DMT were patients with progressive-MS.

Many DMTs are currently available for relapsing MS. In addition, it is now welldemonstrated that early effective treatment reduces long-term disability ${ }^{3,14-16}$. Despite these data and although access to treatment is easy for all French patients and reimbursed by the healthcare system, the number of untreated pwMS among those seen in expert centers is high. The proportion of untreated patients is close to that reported in a large Danish cohort, in which $28 \%$ of patients were untreated. This European country has a similar social system to that of France, with a minimal cost of treatment for the patients ${ }^{6}$. In the same study, it was noted that $43 \%$ of US pwMS were untreated. A previous nation-wide study was conducted in France, including all pwMS in the French national health insurance databases (97\% of the French general population). Patients were identified over the period from 2010 to $2015^{17}$. In this exhaustive study, $46 \%$ of the French MS population was untreated. Compared to the $31 \%$ observed for patients seen in MS expert centers, it is probable that patients followed in such centers are more prone to take a DMT and/or that neurologists working in these centers are more prone to propose a DMT, although there is a center effect. Of note, $26 \%$ of the pwMS had never consulted a neurologist during the six year-period of the previous study ${ }^{17}$. The untreated group is composed of a large majority of progressive MS patients (68.8\%). Progressive MS patients are known to present with a higher EDSS and are less frequently treated as few patients can have a benefit using currently available DMTs. Thus, the currently untreated group has the highest EDSS.

Approaches to MS management differ across Europe, based on the perceived risks and benefits of DMTs. We hypothesize that if the benefit/risk ratio was favorable for every single patient with MS, reducing the relapse risk, the risk of progression and the risk of long-term disability, without any side effect, every single patient with MS should receive a DMT. As it 
is not the case, we suggest that our data support the fact that there still is an unmet need for MS treatment, especially for progressive MS. Other studies would be necessary to determine if in the long-term all patients would gain more than they could lose from DMT. However, the methodology of the present study was not suitable to know which was the reasoning behind a decision not to treat. In France, such decision is usually shared between the neurologist and the patient. Thus, if both the neurologist and the patient have the feeling that the disease is not very active, a DMT is less likely to be prescribed, especially if previously tried DMTs had induced side effects. The present data are in favour of an overall good evaluation of the benefit/risk ratio of the DMTs, patients with less to gain being reasonably identified. The most counter-intuitive result concerned the $15 \%$ of patients with RR-MS seen in an expert center that were not receiving a DMT. Even if we consider that benign MS can go untreated, these patients do not represent more than $3 \%$ of the general MS population ${ }^{18}$, although the natural history of MS appears milder in the recent years, probably as a result of an interplay between several factors including changes in the diagnostic criteria, changes in the epidemiology of MS, impact of early and appropriate DMT and improvement of the general state of health in the population ${ }^{19}$. A possible explanation of why so many patients were going untreated is the prevalence of side effects, which have a strong impact on the persistence of treatment. In the present study, nearly $40 \%$ of patients with a single relapse and RR-MS patients that were previously treated stopped their DMT due to side effects and stayed untreated thereafter. Although many DMTs are available, with minimal side effects for many patients, reducing the side effects of first-line DMT is still a major challenge for improving the persistence of treatment ${ }^{20,21}$. This partially explains why $8 \%$ of RR-MS patients had previously been treated, with a median of two different DMTs, and were no longer being treated.

Currently-treated RR-MS patients had used a DMT for $61 \%$ of the time since disease onset. This parameter mainly highlights that many patients were not treated quickly after the first clinical event (4.6 \pm 5.9 years), as well as that there were gaps between different DMTs for some patients. Some of these gaps can be explained by pregnancy and this factor should be explored in future studies. For cases that had begun several years before, neurologists were waiting for a second event to make the diagnosis and propose a DMT. As the diagnosis can be made faster with more recent criteria ${ }^{22,23}$, it will be informative in the future to explore whether the time between the first clinical event and DMT initiation decreases and the proportion of time receiving a DMT increases. Therapeutic inertia is prone to slow down 
such changes in management, although such phenomenon is supposed to be less pronounced in tertiary care centers with neurologists with a high expertise for MS care ${ }^{24}$.

Until recently, few therapeutic options, other than symptomatic treatment, were available for patients with progressive $\mathrm{MS}^{25,26}$. Ocrelizumab was approved in 2017 for patients with earlystage PP-MS ${ }^{27}$ and siponimod in 2019 for SP-MS, associated with clinical or radiological inflammatory activity ${ }^{28}$. Although DMTs used during clinical trials were included, the lack of labeled effective treatments during the study period explains the low prevalence of DMT use in this sub-group, particularly for PP-MS. In addition, in other observational studies, patients $>60$ years of age and those with SP-MS had no major risk when discontinuing $\mathrm{DMT}^{29,30}$. Despite these obvious limits, around $45 \%$ of all progressive MS patients were receiving a DMT. In this sub-group, anti-CD20, were used in a significant proportion of patients during study period, probably anticipating ocrelizumab's approval. For patients with non-active progressive MS, mycophenolate mofetil and methotrexate were frequently used (Table S1), although these drugs are not approved and have very limited evidence of efficacy ${ }^{31,32}$. We hypothesize that it is difficult to accept for some patients not to receive any DMT, especially when they are seeking care in a tertiary center, and that neurologists propose in such cases treatments with low perceived risk.

As the present study was conducted on data acquired from 2016 to 2017, it is understandable that patients with a single relapse who did not fulfil the 2010 McDonald criteria (31\%) were infrequently receiving a DMT. Fulfilling or not the McDonald criteria at the end of the follow up was the most important variable explaining the use or not of a DMT (70\% fulfilling the criteria for those receiving a DMT and $45 \%$ for those who were not). Since the publication of the new MS diagnostic criteria ${ }^{33}$, more patients experiencing typical CIS can be diagnosed with MS and receive a DMT. Thus, performing the same study in the near future, focusing on data acquired since 2018, may show a change in practice, with more patients with CIS receiving a DMT.

\section{Limitations}

First, this study was conducted in MS expert centers. Thus, it corresponds to tertiary care and cannot be extrapolated to all MS patients $(21,189$ patients seen among the 100,000 pwMS in France). As discussed above, the proportion of treated patients is lower in the general MS population. Indeed, some of these patients do not even see a neurologist. Thus, the true number of untreated pwMS is even higher than that reported in the present study. Second, we 
don't have information concerning who decided not to treat. Most neurologists share the decision with the patients, but in some cases, we can imagine that the decision was mainly coming from the patients and in others, from the neurologists. Third, it is not possible to know whether patients with a single clinical event fulfilled the 2017 McDonald criteria for RR-MS. Only data concerning the 2010 criteria were available, although such a parameter could have had an influence on the treatment decision. Fourth, among never-treated MS patients, some may have been seen in an MS expert center for the first time during the study period and the diagnosis made retrospectively at that point. Thus, it is understandable that these patients were not treated before the diagnosis was made. Fifth, spinal cord lesion load can have an impact on treatment decision. Unfortunately, only a minority of patients (8134/21189, i.e. $38.4 \%)$ had at least one spinal MRI recorded in the database and we decided not to use such data. Finally, to know whether the absence of DMT use is deleterious would require a follow-up of at least two years to assess the evolution of the EDSS, which was not possible with the design of the present study.

In conclusion, the present study shows that a significant proportion of pwMS followed in expert centers were not receiving DMT, including $15 \%$ of patients with RR-MS, despite a large choice of effective and generally well-tolerated treatments. Patients with a single clinical event and progressive MS were less likely to receive a DMT. These results are likely to evolve in the coming years, with a higher proportion of patients treated, as diagnostic criteria have evolved for first demyelinating events and as new treatments are now available for progressive MS. Nonetheless, these results highlight several of the unmet medical needs in the treatment of pwMS.

\section{Acknowledgements}

The authors thank the participating MS expert centers and the Observatoire Français de la Sclérose en Plaques (OFSEP), which made it possible to carry out this study (Appendix 3). OFSEP (Observatoire Français de la Sclérose en Plaques) is supported by grant ANR-10COHO-002 from the French state and managed by the Agence Nationale de la Recherche within the framework of the Investments for the Future program, by the Eugène Devic EDMUS Foundation Against Multiple Sclerosis, and by the ARSEP Foundation. The study protocol was elaborated by Drs Fouchard, Moisset and Clavelou in collaboration with the OFSEP national coordinating center and reviewed by the OFSEP Scientific Committee. 


\section{Conflicts of interest:}

Xavier Moisset has received personal fees from Lilly, TBWA, Teva, Novartis, Roche, Biogen, Sanofi-Genzyme, and Merck-Serono and non-financial support from SOS Oxygène, Boehringer, and Bristol Myers Squibb not related to the submitted work.

Audrey-Anne Fouchard has received personal fees or non-financial support from Genzyme, Merck-Serono and Pfizer not related to the submitted work.

Bruno Pereira has received fees from Biogen.

Frédéric Taithe has received personal fees or non-financial support from Biogen, Sanofi Aventis, Novartis, Merck Serono, Roche, Genzyme, LFB, and Pfizer not related to the submitted work.

Guillaume Mathey has had travel/accomodations/meeting expenses funded by Biogen, Novartis, Sanofi-Genzyme, Merck, Teva, and Roche.

Gilles Edan has received consultancy and lecture fees from Bayer-Schering, Biogen, LFB, Merck, Novartis, Roche, and Sanofi and research grants from Bayer, Biogen, Genzyme, Merck, Novartis, Roche, Teva, and the ARSEP Foundation. He has been principal investigator in phase 2 and 3 clinical studies conducted by Bayer, Biogen, Merck, Novartis, Sanofi-Aventis Teva, and four academic programs (Programmes Hospitaliers de Recherche Clinique, PHRC) on MS sponsored by Rennes University Hospital.

Jonathan Ciron has received personal compensation for consulting, serving on a scientific advisory board, speaking, or other activities from Biogen, Novartis, Merck, Genzyme, Roche, and Teva not related to this study.

Bruno Brochet has received consulting and lecture fees from Actelion, Bayer, Celgene, Biogen, MedDay, Merck KGaA (Darmstadt, Germany), Novartis, Roche, Sanofi-Genzyme, and Teva.

Jérôme De Sèze has received consulting and lecture fees, travel grants, and unconditional research support from MedDay, Biogen, Genzyme, Novartis, Merck Serono, Roche, Sanofi Aventis, and Teva Pharma.

Caroline Papeix has received consulting and lecturing fees and travel grants from Biogen, Novartis, Merck, Roche, Sanofi, Teva Pharma and MEDday. 
Patrick Vermersch has received honoraria and consulting fees from Biogen, Sanofi-Genzyme, Novartis, Teva, Merck, Roche, Servier, Celgene, MedDay, and Almirall and research support from Biogen, Novartis, Sanofi-Genzyme, Roche, and Merck.

Pierre Labauge has received consulting and lecturing fees, travel grants, and unconditional research support from Biogen, Genzyme, Novartis, Merck Serono, Roche, and Teva Pharma.

Gilles Defer has received personal compensation as a member of the scientific advisory board from Biogen Idec, Novartis, Genzyme, and Teva Pharmaceutical Industries Ltd and has received funding for travel and/or speaker honoraria from Merck Serono, Biogen Idec, Novartis, Genzyme, and Teva Pharmaceutical Industries. His institution has received grants supporting research in his department from Merck Serono, Biogen Idec, Novartis, and Genzyme.

Christine Lebrun-Frenay has received consulting or lectures fees from MedDay, Sanofi, Genzyme, Roche, and Novartis.

Thibault Moreau has received fees as scientific adviser from Biogen, MedDay, Novartis, Genzyme, and Sanofi.

David Axel Laplaud has received consulting and lecture fees, travel grants, and unconditional research support from Biogen, Genzyme, Novartis, Merck Serono, Roche, Sanofi Aventis, and Teva Pharma.

Eric Berger has received research support from Biogen and honoraria and consulting fees from Novartis, Sanofi Aventis, Biogen, Genzyme, Roche, and Teva Pharma.

Jean Pelletier has nothing to disclose.

Bruno Stankoff has nothing to disclose.

Olivier Gout has received personal fees and non-financial support from MedDay Pharmaceuticals, Biogen, Novartis, Genzyme, Merck Serono, Novartis, Roche, Elivie, and Teva not related to the submitted work.

Eric Thouvenot has received consulting and lecturing fees, travel grants or unconditional research support from the following pharmaceutical companies: Actelion, Biogen, Celgene, Genzyme, Medday, Merck Serono, Novartis, Roche, Teva pharma not related to the submitted work. 
Olivier Heinzlef has received consulting and lecture fees from Bayer Schering, Merck, Teva, Genzyme, Novartis, Almirall, and Biogen Idec, travel grants from Novartis, Teva, Genzyme, Merck Serono, and Biogen Idec, and research support from Roche, Merck, and Novartis.

Abdullatif Al-Khedr has nothing to disclose.

Bertrand Bourre has received funding for travel and honoraria from Biogen Idec, MedDay Pharmaceuticals, Merck Serono, Novartis, Sanofi, Roche, and Teva.

Olivier Casez has nothing to disclose.

Philippe Cabre has received funding for travel by Novartis.

Alexis Montcuquet has had travel/accommodations/meeting expenses funded by Biogen, Novartis, Sanofi-Genzyme, Merck, Teva, and Roche.

Alain Créange has nothing to disclose.

Jean-Philippe Camdessanché has received fees for lectures, consulting, writing of articles, and training courses from Akcea, Alnylam, Biogen, CSL-Behring, Genzyme, Grifols, LFB, Merck, Novartis, Pfizer, Pharmalliance, Teva, Editions Scientifiques L\&C, Edimark, Expression Santé, Natus, Scien, and SNF-Floerger not related to the submitted work.

Serge Bakchine has nothing to disclose.

Aude Maurousset has received funding for travel from Merck Serono, Teva, Novartis, Sanofi-Genzyme, Biogen and Roche and honoria from Biogen, Novartis, and Roche not related to the submitted work.

Karolina Hankiewicz has nothing to disclose.

Corinne Pottier has nothing to disclose.

Nicolas Maubeuge has nothing to disclose.

Dalia Dimitri Boulos has nothing to disclose.

Chantal Nifle has nothing to disclose.

Sandra Vukusic has received grants, personal fees, and non-financial support from Biogen, Celgene, Geneuro, Genzyme, MedDay, Merck-Serono, Novartis, Roche, Sanofi, and Teva not related to the submitted work. 
Pierre Clavelou reports fees from Teva, Sanofi, Merck, Roche, Novartis, Actelion and nonfinancial support from MedDay and Biogen not related to the submitted work. 


\section{References}

1. Brown JWL, Coles A, Horakova D, et al. Association of Initial Disease-Modifying Therapy With Later Conversion to Secondary Progressive Multiple Sclerosis. JAMA. 2019;321(2):175-187. doi:10.1001/jama.2018.20588

2. Harding K, Williams O, Willis M, et al. Clinical Outcomes of Escalation vs Early Intensive Disease-Modifying Therapy in Patients With Multiple Sclerosis. JAMA Neurol. 2019;76(5):536-541. doi:10.1001/jamaneurol.2018.4905

3. Ontaneda D, Tallantyre E, Kalincik T, Planchon SM, Evangelou N. Early highly effective versus escalation treatment approaches in relapsing multiple sclerosis. Lancet Neurol. 2019;18(10):973-980. doi:10.1016/S1474-4422(19)30151-6

4. Montalban X, Gold R, Thompson AJ, et al. ECTRIMS/EAN Guideline on the pharmacological treatment of people with multiple sclerosis. Mult Scler Houndmills Basingstoke Engl. 2018;24(2):96-120. doi:10.1177/1352458517751049

5. Rae-Grant A, Day GS, Marrie RA, et al. Comprehensive systematic review summary: Disease-modifying therapies for adults with multiple sclerosis: Report of the Guideline Development, Dissemination, and Implementation Subcommittee of the American Academy of Neurology. Neurology. 2018;90(17):789-800.

doi:10.1212/WNL.0000000000005345

6. Nørgaard M, Foch C, Magyari M, et al. Untreated Patients with Multiple Sclerosis: Prevalence and Characteristics in Denmark and in the United States (P4.2-060). Neurology. 2019;92(15 Supplement):P4.2-060.

7. Simacek KF, Ko JJ, Moreton D, Varga S, Johnson K, Katic BJ. The Impact of DiseaseModifying Therapy Access Barriers on People With Multiple Sclerosis: Mixed-Methods Study. J Med Internet Res. 2018;20(10). doi:10.2196/11168

8. Hartung DM. Economics and Cost-Effectiveness of Multiple Sclerosis Therapies in the USA. Neurother J Am Soc Exp Neurother. 2017;14(4):1018-1026. doi:10.1007/s13311017-0566-3 
9. Vukusic S, Casey R, Rollot F, et al. Observatoire Français de la Sclérose en Plaques (OFSEP): A unique multimodal nationwide MS registry in France. Mult Scler Houndmills Basingstoke Engl. 2020;26(1):118-122. doi:10.1177/1352458518815602

10. Confavreux C, Compston DA, Hommes OR, McDonald WI, Thompson AJ. EDMUS, a European database for multiple sclerosis. J Neurol Neurosurg Psychiatry. 1992;55(8):671-676.

11. Bender R, Lange S. Adjusting for multiple testing--when and how? J Clin Epidemiol. 2001;54(4):343-349. doi:10.1016/s0895-4356(00)00314-0

12. Feise RJ. Do multiple outcome measures require p-value adjustment? BMC Med Res Methodol. 2002;2:8.

13. Krzywinski M, Altman N. Classification and regression trees. Nat Methods. 2017;14(8):757-758. doi:10.1038/nmeth.4370

14. Kappos L, Freedman MS, Polman CH, et al. Effect of early versus delayed interferon beta- $1 \mathrm{~b}$ treatment on disability after a first clinical event suggestive of multiple sclerosis: a 3-year follow-up analysis of the BENEFIT study. Lancet Lond Engl. 2007;370(9585):389-397. doi:10.1016/S0140-6736(07)61194-5

15. Leray E, Yaouanq J, Le Page E, et al. Evidence for a two-stage disability progression in multiple sclerosis. Brain J Neurol. 2010;133(Pt 7):1900-1913. doi:10.1093/brain/awq076

16. Chalmer TA, Baggesen LM, Nørgaard M, et al. Early versus later treatment start in multiple sclerosis: a register-based cohort study. Eur J Neurol. 2018;25(10):1262-e110. doi:10.1111/ene.13692

17. Roux J, Guilleux A, Grimaud O, Leray E. Care-seeking of patients with multiple sclerosis over 2010-2015 in France: a nationwide study using health administrative data. ECTRIMS Online Library. P1000. Published 2018. Accessed May 14, 2020. https://onlinelibrary.ectrims-congress.eu/ectrims/2018/ectrims2018/228842/jonathan.roux.care-seeking.of.patients.with.multiple.sclerosis.over.20102015.html 
18. Tallantyre EC, Major PC, Atherton MJ, et al. How common is truly benign MS in a UK population? J Neurol Neurosurg Psychiatry. 2019;90(5):522-528. doi:10.1136/jnnp2018-318802

19. Sorensen PS, Sellebjerg F, Hartung H-P, Montalban X, Comi G, Tintoré M. The apparently milder course of multiple sclerosis: changes in the diagnostic criteria, therapy and natural history. Brain J Neurol. 2020;143(9):2637-2652. doi:10.1093/brain/awaa145

20. Condé S, Moisset X, Pereira B, et al. Dimethyl fumarate and teriflunomide for multiple sclerosis in a real-life setting: a French retrospective cohort study. Eur J Neurol. Published online October 15, 2018. doi:10.1111/ene.13839

21. Lahdenperä S, Soilu-Hänninen M, Kuusisto H-M, Atula S, Junnila J, Berglund A. Medication adherence/persistence among patients with active multiple sclerosis in Finland. Acta Neurol Scand. Published online June 19, 2020. doi:10.1111/ane.13301

22. Brownlee WJ, Swanton JK, Altmann DR, Ciccarelli O, Miller DH. Earlier and more frequent diagnosis of multiple sclerosis using the McDonald criteria. J Neurol Neurosurg Psychiatry. 2015;86(5):584-585. doi:10.1136/jnnp-2014-308675

23. McNicholas N, Lockhart A, Yap SM, et al. New versus old: Implications of evolving diagnostic criteria for relapsing-remitting multiple sclerosis. Mult Scler Houndmills Basingstoke Engl. 2019;25(6):867-870. doi:10.1177/1352458518770088

24. Almusalam N, Oh J, Terzaghi M, et al. Comparison of Physician Therapeutic Inertia for Management of Patients With Multiple Sclerosis in Canada, Argentina, Chile, and Spain. JAMA Netw Open. 2019;2(7):e197093. doi:10.1001/jamanetworkopen.2019.7093

25. Fox RJ, Thompson A, Baker D, et al. Setting a research agenda for progressive multiple sclerosis: the International Collaborative on Progressive MS. Mult Scler Houndmills Basingstoke Engl. 2012;18(11):1534-1540. doi:10.1177/1352458512458169

26. Shirani A, Okuda DT, Stüve O. Therapeutic Advances and Future Prospects in Progressive Forms of Multiple Sclerosis. Neurother J Am Soc Exp Neurother. 2016;13(1):58-69. doi:10.1007/s13311-015-0409-z 
27. Montalban X, Hauser SL, Kappos L, et al. Ocrelizumab versus Placebo in Primary Progressive Multiple Sclerosis. N Engl J Med. 2017;376(3):209-220. doi:10.1056/NEJMoa1606468

28. Kappos L, Bar-Or A, Cree BAC, et al. Siponimod versus placebo in secondary progressive multiple sclerosis (EXPAND): a double-blind, randomised, phase 3 study. Lancet Lond Engl. 2018;391(10127):1263-1273. doi:10.1016/S0140-6736(18)30475-6

29. Bonenfant J, Bajeux E, Deburghgraeve V, Le Page E, Edan G, Kerbrat A. Can we stop immunomodulatory treatments in secondary progressive multiple sclerosis? Eur J Neurol. 2017;24(2):237-244. doi:10.1111/ene.13181

30. Hua LH, Fan TH, Conway D, Thompson N, Kinzy TG. Discontinuation of diseasemodifying therapy in patients with multiple sclerosis over age 60. Mult Scler Houndmills Basingstoke Engl. 2019;25(5):699-708. doi:10.1177/1352458518765656

31. Michel L, Vukusic S, De Seze J, et al. Mycophenolate mofetil in multiple sclerosis: a multicentre retrospective study on 344 patients. J Neurol Neurosurg Psychiatry. 2014;85(3):279-283. doi:10.1136/jnnp-2013-305298

32. Goodkin DE, Rudick RA, VanderBrug Medendorp S, et al. Low-dose (7.5 mg) oral methotrexate reduces the rate of progression in chronic progressive multiple sclerosis. Ann Neurol. 1995;37(1):30-40. doi:10.1002/ana.410370108

33. Thompson AJ, Banwell BL, Barkhof F, et al. Diagnosis of multiple sclerosis: 2017 revisions of the McDonald criteria. Lancet Neurol. 2018;17(2):162-173. doi:10.1016/S1474-4422(17)30470-2 
Table 1. Description of the overall population and the three sub-groups according to disease modifying treatment use. Never treated (A), Currently untreated (B), Currently treated (C). Statistical comparisons performed using the Tukey-Kramer or Dunn tests. A twosided $\mathrm{p}$ value $<0.05$ was considered statistically significant. RR: relapsing remitting with at least 2 relapses, SP: secondary progressive, PP: primary progressive.

Table 2. Presentation of the four sub-groups of patients with relapsing-remitting multiple sclerosis (RR-MS). * corresponds to $\mathrm{p}<0.001$ for comparison with currently treated RR-MS patients. ARR: annualized relapse rate.

Table 3. Presentation of the four sub-groups of patients with a single relapse. * corresponds to $p<0.001$ for comparison with currently-treated patients. Disease duration is expressed as the median and interquartile range, as the distribution was non-normal.

Table 4. Presentation of the four sub-groups of patients with secondary progressive multiple sclerosis (SP-MS). * corresponds to $\mathrm{p}<0.001$ for comparison with currentlytreated SP-MS patients.

Table 5. Presentation of the four sub-groups of patients with primary progressive multiple sclerosis (PP-MS). * corresponds to $\mathrm{p}<0.001$ for comparison with currentlytreated PP-MS patients.

Figure 1. Flow diagram of patients seen at least once during the one-year study period (June 15, 2016 to June 14, 2017).

Supplementary files: 
Table S1. Five most frequently used disease modifying therapies (DMTs) for each disease course, both previously and currently used.

Figure S1. Classification tree presenting the probability of never having been treated. RR: relapsing remitting with at least 2 relapses, SP: secondary progressive, PP: primary progressive. 
Table 1. Description of the overall population and the three sub-groups according to disease modifying treatment use. Never treated (A), Currently untreated (B), Currently treated (C). Statistical comparisons performed using the Tukey-Kramer or Dunn tests. A twosided $\mathrm{p}$ value $<0.05$ was considered statistically significant. RR: relapsing remitting with at least 2 relapses, SP: secondary progressive, PP: primary progressive.

\section{Demographic} characteristics

Female sex, \% (n)

Age at disease

diagnosis (years)

Age at first

appointment during

study period

\section{Clinical}

characteristics

Disease duration

(years)

Disease course, n (\%)

- Single relapse

RR

- SP

- PP

EDSS

\begin{tabular}{|c|c|c|c|c|}
\hline $\begin{array}{c}\text { Overall } \\
\text { population } \mathrm{N} \\
=\mathbf{2 1 , 1 8 9}\end{array}$ & $\begin{array}{c}\text { Never } \\
\text { treated } \\
\mathrm{N}=\mathbf{3 , 1 2 2}\end{array}$ & $\begin{array}{l}\text { Currently } \\
\text { untreated } \\
\mathrm{N}=\mathbf{3 , 5 0 9}\end{array}$ & $\begin{array}{c}\text { Currently } \\
\text { treated } \\
\mathrm{N}=\mathbf{1 4 , 5 5 8}\end{array}$ & Statistics \\
\hline $71.2(15,075)$ & $68.9(2,152)$ & $69.4(2,436)$ & $72.0(10,487)$ & \\
\hline $33.0 \pm 10.8$ & $38.2 \pm 12.2$ & $34.2 \pm 10.7$ & $31.6 \pm 10.1$ & $\mathrm{~A} \neq \mathrm{B} \neq \mathrm{C}$ \\
\hline $47.1 \pm 13.1$ & $50.8 \pm 14.9$ & $54.9 \pm 12.1$ & $44.4 \pm 11.9$ & $\mathrm{~A} \neq \mathrm{B} \neq \mathrm{C}$ \\
\hline $14.1 \pm 10.4$ & $12.6 \pm 12.4$ & $20.7 \pm 11.0$ & $12.9 \pm 9.1$ & $\begin{array}{c}\mathrm{A} \neq \mathrm{B} \\
\mathrm{B} \neq \mathrm{C}\end{array}$ \\
\hline $2,718(12.8)$ & 985 (31.6) & $158(4.5)$ & $1,575(10.8)$ & \\
\hline $11,693(55.2)$ & $793(25.4)$ & $936(26.7)$ & 9,964 (68.4) & $\mathrm{A} \neq \mathrm{B} \neq \mathrm{C}$ \\
\hline $4,289(20.2)$ & $498(16.0)$ & $1,662(47.4)$ & $2,129(14.6)$ & \\
\hline 2,489 (11.8) & $846(27.1)$ & $753(21.5)$ & $890(6.1)$ & \\
\hline $3.4 \pm 2.4$ & $3.2 \pm 2.5$ & $5.2 \pm 2.4$ & $2.9 \pm 2.2$ & $\mathrm{~A} \neq \mathrm{B} \neq \mathrm{C}$ \\
\hline
\end{tabular}


Table 2. Presentation of the four sub-groups of patients with relapsing-remitting multiple sclerosis (RR-MS). * corresponds to $\mathrm{p}<0.001$ for comparison with currently treated RR-MS patients. ARR: annualized relapse rate.

\begin{tabular}{|c|c|c|c|c|c|}
\hline & $\begin{array}{l}\text { Overall } \\
\text { RR-MS }\end{array}$ & $\begin{array}{c}\text { Currently } \\
\text { treated }\end{array}$ & $\begin{array}{r}\text { Current } \\
\mathrm{N} \\
(8\end{array}$ & $\begin{array}{l}\text { y untreated } \\
=936 \\
0 \%)\end{array}$ & $\begin{array}{l}\text { Never } \\
\text { treated }\end{array}$ \\
\hline & $\begin{array}{c}\text { patients } \\
\mathrm{N}=\mathbf{1 1 , 6 9 3}\end{array}$ & $\begin{array}{c}N=9,964 \\
(85.2 \%)\end{array}$ & $\begin{array}{c}\text { Previously treated } \\
\qquad \mathrm{N}=860 \\
(7.4 \%)\end{array}$ & $\begin{array}{c}\text { Treated in the } 6 \\
\text { months after study } \\
\text { period } \mathrm{N}=76(0.6 \%)\end{array}$ & $\begin{array}{c}N=793 \\
(6.8 \%)\end{array}$ \\
\hline Age, years & $43.2 \pm 11.4$ & $42.5 \pm 11.0$ & $48.3 \pm 12.4^{*}$ & $40.3 \pm 11.7$ & $47.3 \pm 13.2 *$ \\
\hline $\begin{array}{l}\text { Female sex, } \\
\%(\mathrm{n})\end{array}$ & $\begin{array}{l}75.7 \\
(8,856)\end{array}$ & $\begin{array}{l}75.1 \\
(7,478)\end{array}$ & $80.8(695)^{*}$ & $77.6(59)$ & $78.7(624)$ \\
\hline EDSS & $2.3 \pm 1.8$ & $2.3 \pm 1.7$ & $2.7 \pm 2.0 *$ & $2.2 \pm 1.3$ & $1.9 \pm 1.7^{*}$ \\
\hline $\begin{array}{l}\text { Disease } \\
\text { duration, } \\
\text { years }\end{array}$ & $12.8 \pm 8.5$ & $12.4 \pm 8.1$ & $16.5 \pm 9.2^{*}$ & $9.9 \pm 8.6^{*}$ & $14.7 \pm 11.2^{*}$ \\
\hline $\begin{array}{l}\text { Age at } \\
\text { disease } \\
\text { onset, years }\end{array}$ & $30.4 \pm 9.5$ & $30.1 \pm 9.4$ & $31.8 \pm 10.1^{*}$ & $30.4 \pm 9.6$ & $32.4 \pm 10.4^{*}$ \\
\hline $\begin{array}{l}\text { MRI } \geq 9 \\
\text { lesions }(\mathrm{n}= \\
9,513)\end{array}$ & $\begin{array}{l}76.9 \\
(7,314)\end{array}$ & $\begin{array}{l}78.4 \\
(6,445)\end{array}$ & $74.3(459)$ & $68.1(49)$ & $59.5(361)^{*}$ \\
\hline 2-year ARR & $0.32 \pm 0.49$ & $0.34 \pm 0.50$ & $0.22 \pm 0.43^{*}$ & $0.32 \pm 0.41$ & $0.23 \pm 0.36^{*}$ \\
\hline 5-year ARR & $0.33 \pm 0.33$ & $0.34 \pm 0.34$ & $0.26 \pm 0.34 *$ & $0.28 \pm 0.30$ & $0.19 \pm 0.22 *$ \\
\hline
\end{tabular}


Table 3. Presentation of the four sub-groups of patients with a single relapse. * corresponds to $\mathrm{p}<0.001$ for comparison with currently-treated patients. Disease duration is expressed as the median and interquartile range, as the distribution was non-normal.

\begin{tabular}{|c|c|c|c|c|c|}
\hline & \multirow{2}{*}{$\begin{array}{c}\text { Overall } \\
\text { patients with } \\
\text { a single } \\
\text { relapse } \\
\mathrm{N}=\mathbf{2 , 7 1 8}\end{array}$} & \multirow{2}{*}{$\begin{array}{c}\text { Currently } \\
\text { treated } \\
\mathrm{N}=1,575 \\
(\mathbf{5 7 . 9 \% )}\end{array}$} & \multicolumn{2}{|c|}{$\begin{array}{l}\text { Currently untreated } \\
\qquad \mathrm{N}=158(5.8 \%)\end{array}$} & \multirow[b]{2}{*}{$\begin{array}{l}\text { Never treated } \\
\qquad \begin{array}{c}\mathbf{N}=985 \\
(36.2 \%)\end{array}\end{array}$} \\
\hline & & & $\begin{array}{l}\text { Previously treated } \\
\qquad \mathrm{N}=107 \\
(3.9 \%)\end{array}$ & $\begin{array}{l}\text { Treated in the } 6 \\
\text { months after } \\
\text { study period } \\
\mathrm{N}=51(1.9 \%)\end{array}$ & \\
\hline Age, years & $40.0 \pm 11.9$ & $39.2 \pm 11.4$ & $45.4 \pm 11.9^{*}$ & $37.1 \pm 10.0$ & $40.7 \pm 12.5^{*}$ \\
\hline $\begin{array}{l}\text { Female sex, } \\
\%(n)\end{array}$ & $71.0(1,929)$ & $70.0(1,102)$ & $72.9(78)$ & $78.4(40)$ & $72.0(709)$ \\
\hline EDSS & $1.4 \pm 1.5$ & $1.4 \pm 1.5$ & $1.4 \pm 1.7$ & $1.8 \pm 1.6$ & $1.3 \pm 1.5$ \\
\hline $\begin{array}{l}\text { MRI } \geq 9 \\
\text { lesions }(n= \\
2,347)\end{array}$ & $58.8(1,381)$ & $69.7(946)$ & $63.5(45)$ & $76.5(39)$ & $40.4(349)^{*}$ \\
\hline $\begin{array}{l}\text { McDonald's } \\
2010 \text { criteria } \\
\text { at last follow- } \\
\text { up }\end{array}$ & $60.6(1,646)$ & $70.2(1,105)$ & $55.1(59)^{*}$ & $80.4(41)$ & $44.8(441)^{*}$ \\
\hline $\begin{array}{l}\text { Disease } \\
\text { duration, } \\
\text { years }\end{array}$ & $2.3[0.7-5.5]$ & 2.9 [1.2-5.9] & $7.2[4.3-12.2]^{*}$ & $0.3[0.1-2.1]^{*}$ & $1.1[0.3-3.5]^{*}$ \\
\hline $\begin{array}{l}\text { Age at disease } \\
\text { onset, years }\end{array}$ & $35.9 \pm 10.8$ & $34.9 \pm 10.4$ & $36.2 \pm 9.8$ & $35.4 \pm 9.8$ & $37.4 \pm 11.3^{*}$ \\
\hline Optic neuritis & $28.4(772)$ & $29.2(460)$ & $24.3(26)$ & $29.4(15)$ & $27.5(271)$ \\
\hline
\end{tabular}


Table 4. Presentation of the four sub-groups of patients with secondary progressive multiple sclerosis (SP-MS). * corresponds to $\mathrm{p}<0.001$ for comparison with currentlytreated SP-MS patients.

\begin{tabular}{|c|c|c|c|c|c|}
\hline & \multirow{2}{*}{$\begin{array}{l}\text { Overall SP- } \\
\text { MS patients } \\
N=4,289\end{array}$} & \multirow{2}{*}{$\begin{array}{l}\text { Currently } \\
\text { treated } \\
N=2,129 \\
(49.6 \%)\end{array}$} & \multicolumn{2}{|c|}{$\begin{array}{c}\text { Currently untreated } \\
\mathrm{N}=\mathbf{1 , 6 6 2}(\mathbf{3 8 . 8 \%})\end{array}$} & \multirow{2}{*}{$\begin{array}{l}\text { Never treated } \\
\qquad \begin{array}{c}\mathrm{N}=498 \\
(11.6 \%)\end{array}\end{array}$} \\
\hline & & & $\begin{array}{c}\text { Previously } \\
\text { treated } \\
\mathrm{N}=1,645 \\
(38.4 \%)\end{array}$ & $\begin{array}{l}\text { Treated in the } 6 \\
\text { months after } \\
\text { study period } \\
\mathrm{N}=17(0.4 \%)\end{array}$ & \\
\hline Age, years & $56.3 \pm 10.5$ & $53.4 \pm 10.1$ & $58.3 \pm 9.8^{*}$ & $54.6 \pm 9.1$ & $62.1 \pm 10.2 *$ \\
\hline $\begin{array}{l}\text { Female sex, } \\
\%(\mathbf{n})^{*}\end{array}$ & $68.5(2,938)$ & $68.2(1,451)$ & $69.0(1,135)$ & $64.7(11)$ & $68.5(361)$ \\
\hline EDSS & $6.1 \pm 1.4$ & $5.8 \pm 1.3$ & $6.5 \pm 1.4^{*}$ & $6.0 \pm 1.3$ & $5.7 \pm 1.6$ \\
\hline $\begin{array}{l}\text { Disease } \\
\text { duration, } \\
\text { years }\end{array}$ & $24.2 \pm 10.2$ & $21.7 \pm 9.3$ & $26.3 \pm 10.0^{*}$ & $20.9 \pm 10.5$ & $27.8 \pm 11.7^{*}$ \\
\hline $\begin{array}{l}\text { Age at disease } \\
\text { onset, years }\end{array}$ & $32.2 \pm 9.7$ & $31.8 \pm 9.4$ & $32.0 \pm 9.7$ & $33.6 \pm 10.5$ & $34.3 \pm 10.8^{*}$ \\
\hline $\begin{array}{l}\text { Progressive } \\
\text { phase } \\
\text { duration }\end{array}$ & $10.9 \pm 7.6$ & $8.7 \pm 6.6$ & $13.3 \pm 7.6^{*}$ & $6.7 \pm 5.7$ & $12.1 \pm 8.9$ \\
\hline 2-year ARR & $0.14 \pm 0.31$ & $0.20 \pm 0.37$ & $0.08 \pm 0.24^{*}$ & $0.18 \pm 0.30$ & $0.08 \pm 0.21^{*}$ \\
\hline 5-year ARR & $0.17 \pm 0.26$ & $0.23 \pm 0.29$ & $0.11 \pm 0.22^{*}$ & $0.14 \pm 0.17$ & $0.09 \pm 0.15^{*}$ \\
\hline
\end{tabular}


Table 5. Presentation of the four sub-groups of patients with primary progressive multiple sclerosis (PP-MS). * corresponds to $\mathrm{p}<0.001$ for comparison with currentlytreated PP-MS patients.

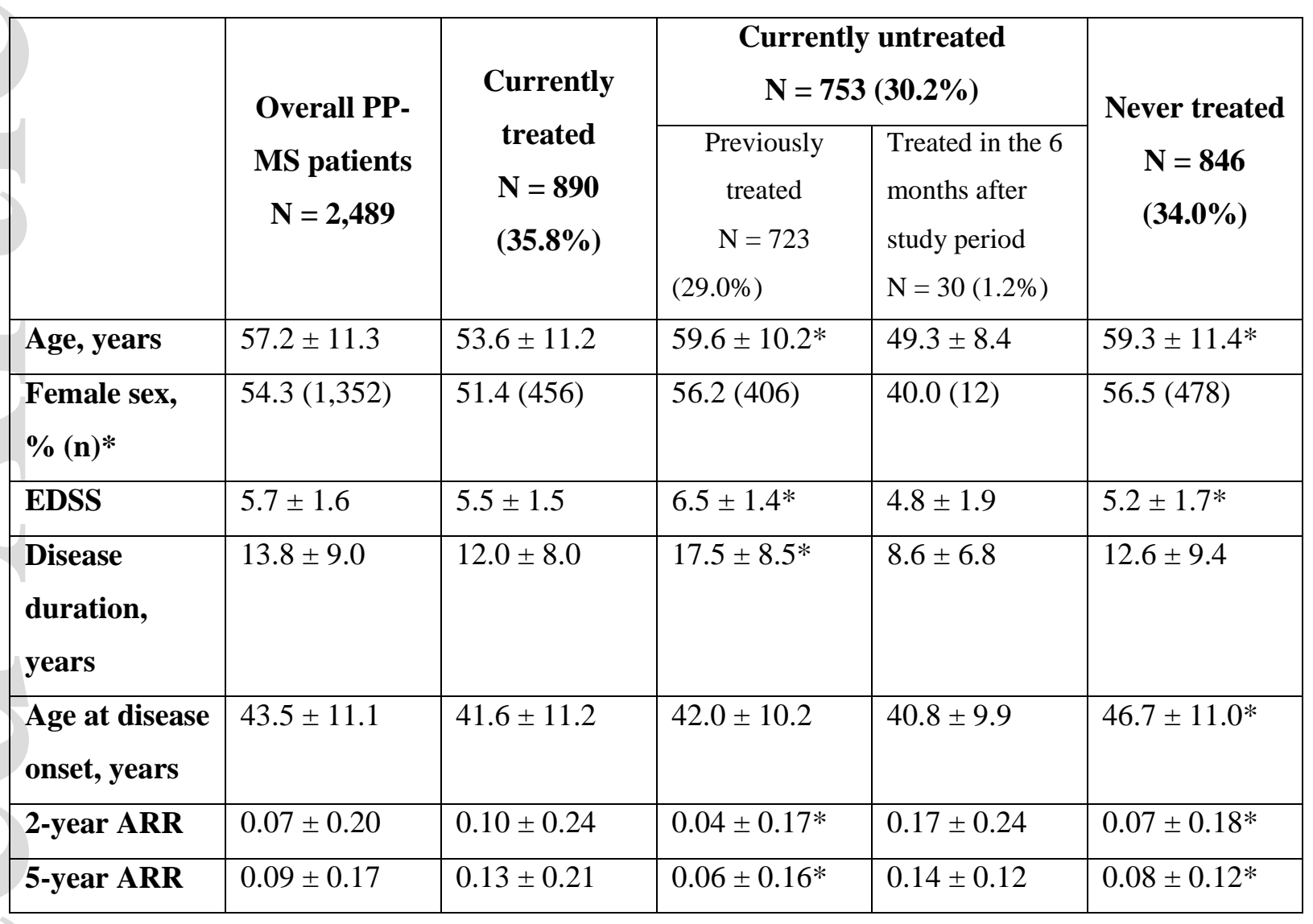




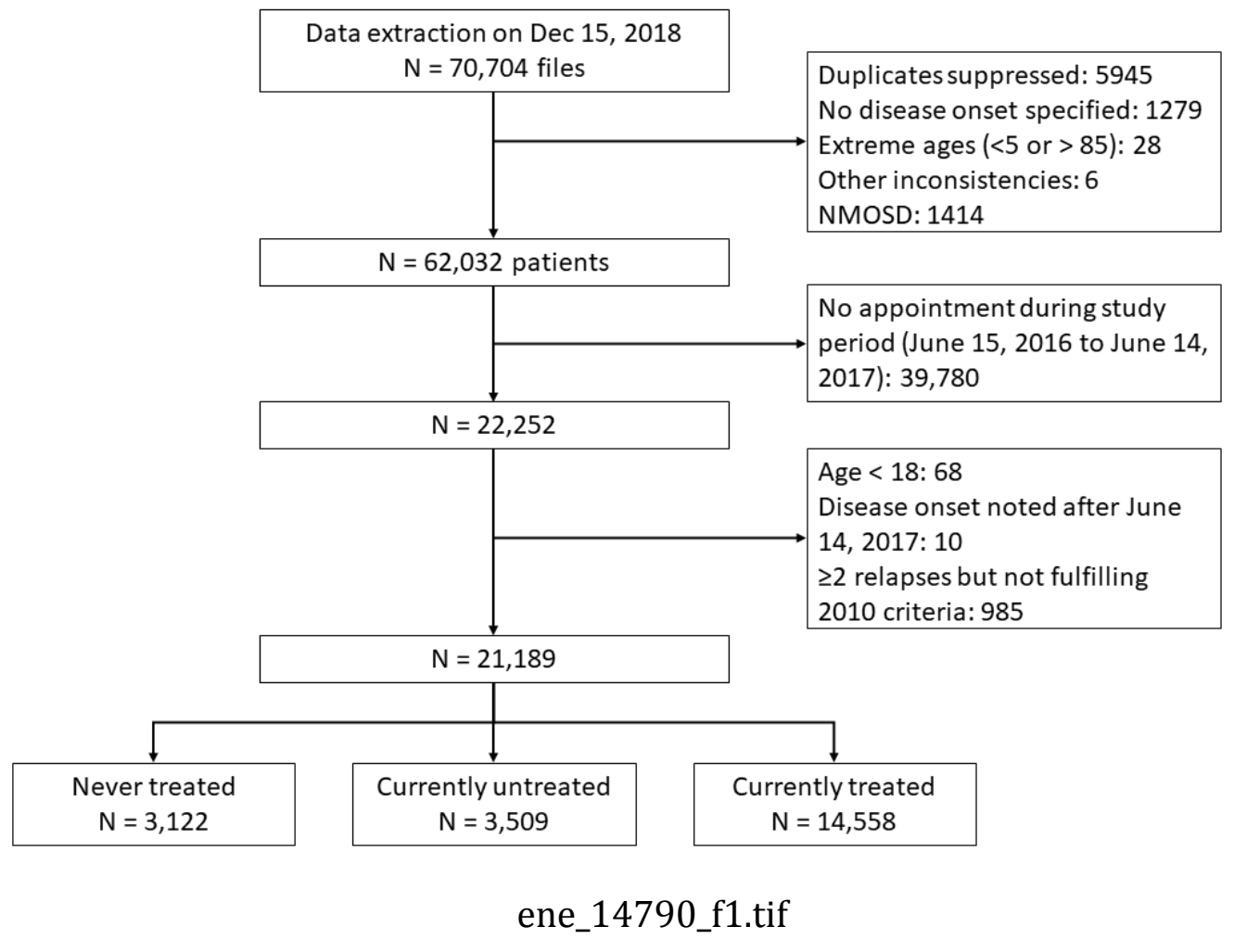

